\title{
Survival analysis of ovarian clear cell carcinoma confined to the ovary with or without comprehensive surgical staging
}

\author{
MASASHI TAKANO $^{1}$, NAOKI SASAKI ${ }^{1}$, TSUNEKAZU KITA ${ }^{1}$, KAZUYA KUDOH ${ }^{1}$, \\ KAZUYUKI FUJII ${ }^{1}$, TOMOYUKI YOSHIKAWA ${ }^{1}$, MASAFUMI KATO ${ }^{1}$, JUNKO HIRATA ${ }^{1}$, \\ KENICHI FURUYA ${ }^{1}$, HITOSHI TSUDA ${ }^{2}$ and YOSHIHIRO KIKUCHI ${ }^{3}$ \\ Departments of ${ }^{1}$ Obstetrics and Gynecology and ${ }^{2}$ Pathology II, National Defense Medical College, \\ Tokorozawa, Saitama 359-8513; ${ }^{3}$ Department of Gynecology, Ohki Memorial Kikuchi \\ Cancer Clinic for Women, Tokorozawa, Saitama 359-1133, Japan
}

Received October 9, 2007; Accepted December 10, 2007

\begin{abstract}
Pure-type clear cell carcinoma (CCC) has been recognized as a distinct subtype of ovarian cancer, showing a resistance to chemotherapy and resulting in poor prognosis. Our aim was to evaluate the effects of complete surgical procedures followed by adjuvant chemotherapy for CCC patients whose tumors were confined to the ovary (pT1M0). During the period of 1987-2005, 56 patients with stage I CCC were identified and two cases were excluded due to retroperitoneal lymph node metastasis. A total of 54 patients were enrolled in the study and divided into two groups: Group A $(n=38,1993-2005)$ underwent complete surgical staging including pelvic and para-aortic lymphadenectomy. Group B $(n=16,1987-1992)$ underwent a hysterectomy, bilateral salpingo-oopherectomy, omentectomy without comprehensive lymphadenectomy. Every patient received six courses of adjuvant chemotherapy using a platinum agent. Survival analysis was estimated by the Kaplan-Meier method and prognostic factors were evaluated using a Cox regression model. The clinical characteristics of the two groups were similar, except for the rate of conventional platinum-based chemotherapy $(\mathrm{p}=0.02)$. Multiple regression survival analysis revealed that the completion of a comprehensive staging operation was the only independent factor for progressionfree survival of stage I CCC patients $(p=0.03)$ and that the chemotherapeutic regimen was not a prognostic factor $(\mathrm{p}=0.43)$. The present study indicates that we should accomplish complete surgical staging procedures for CCC confined to the ovary.
\end{abstract}

Correspondence to: Dr Masashi Takano, Department of Obstetrics and Gynecology, National Defense Medical College, 3-2 Namiki, Tokorozawa, Saitama 359-8513, Japan

E-mail: mastkn@ndmc.ac.jp

Key words: ovarian cancer, clear cell carcinoma, surgical staging, lymphadenectomy, chemotherapy

\section{Introduction}

Ovarian carcinoma is now the leading cause of death in all gynecological malignancies in most developed countries, despite recent improvement of treatment modalities $(1,2)$. The poor prognosis was accounted for largely by a high frequency of advanced cases at the time of diagnosis, although a paclitaxel-based regimen achieved a high clinical response rate of $\sim 70 \%$ (3). The regimen is recognized as the gold standard for ovarian cancer, showing a remarkable impact for not only primary ovarian tumors but also recurrent tumors (4-6). On the other hand, clear cell carcinoma (CCC) of the ovary initially termed by Schiller (7) and characterized by WHO (8) has been identified as having a distinctive behavior in comparison with other histological subtypes. Many publications confirmed that the most distinct difference of CCC tumors was a significant lower rate of response to conventional platinum-based chemotherapy (9-12). Similarly, the response of paclitaxel-based regimen for CCC was from 22 to $56 \%$ (13-15) and the impact for survival improvement was not clearly determined $(16,17)$. Irinotecan hydrochloride, a semisynthetic derivative of camptothecin, has been reported to have a potential therapeutic effect on CCC (18-20), though there has been no large clinical trial confirming survival benefits. The second distinct difference was that CCC tumors showed a high frequency of stage I tumors, roughly accounting for $50 \%$ of all cases $(11,17,21)$. Surgical staging including lymphadenectomy was inevitable for the FIGO staging system (22), though there has been limited studies showing a significant benefit in the patients with tumors in their early stages. Moreover, a clinical significance of complete surgical staging followed by adjuvant chemotherapy for stage I CCC tumors has not yet been established. The aim of our study was to evaluate the effect of staging procedures upon the survival of clinical stage I CCC patients.

\section{Materials and methods}

Patients and tumors. Between 1987 and 2005, cases with pure-type CCC of the ovary were identified by scanning the 
medical records of the National Defense Medical College and a central pathological review by two independent pathologists. Tumors were diagnosed as pure-type CCC if typical clear or hobnail cells growing in a papillary, solid, or a tubulocystic pattern appeared in all or $>90 \%$ of the pathological specimens. During this period, 105 patients were diagnosed with CCC. At our hospital, complete surgical staging including para-aortic lymphadenectomy had been carried out from the beginning of 1993 and the lymph node status of most patients treated before 1992 were not examined comprehensively. One patient diagnosed as CCC of peritoneal origin and 48 cases with pT2 and pT3 tumors were excluded and a total of 56 pT1 cases were found. In these cases, retroperitoneal lymph node metastasis was observed in one case $(11 \%)$ of pT1a and one case $(3 \%)$ of pT1c tumors, and these two cases (pT1N1) were excluded from the present analysis. A total of 54 cases were enrolled in the present study. Thirty-eight patients (Group A), who were treated from 1993 to 2005, underwent complete surgical staging procedures including a hysterectomy, bilateral salpingo-oophorectomy, peritoneal washing, infracolic omentectomy, pelvic lymphadenectomy and para-aortic lymphadenenctomy at the initial operation. Sixteen patients (group B), who were treated from 1987 to 1992, underwent a total hysterectomy, bilateral salpingooophorectomy, peritoneal washing, infracolic omentectomy without comprehensive lymphadenectomy as their primary operation. Pelvic lymphadenectomy was performed from the common, external and internal iliac node and obturator vessel to the femoral ring. Para-aortic lymphadenectomy was performed from the bottom of the left renal vessel including the left infrarenal lymph nodes to the bifurcation of the aorta.

Each patient in the two groups received postoperative chemotherapy after initial surgery. The combination therapy of cyclophosphamide, doxorubicin and cisplatin (CAP) was as follows: one cycle consisted of a drip infusion of $50 \mathrm{mg} / \mathrm{m}^{2}$ cisplatin for $3 \mathrm{~h}$ accompanied by an i.v. injection of $50 \mathrm{mg} / \mathrm{m}^{2}$ doxorubicin and $500 \mathrm{mg} / \mathrm{m}^{2}$ cyclophosphamide and 6 cycles were given every 4 weeks. Paclitaxel and platinum regimen consisted of an infusion of $175-180 \mathrm{mg} / \mathrm{m}^{2}$ of paclitaxel and $50 \mathrm{mg} / \mathrm{m}^{2}$ of cisplatin or carboplatin $(\mathrm{AUC}=5)$ and 6 cycles were given every 3-4 weeks. One cycle of irinotecan hydrochloride and platinum regimen consisted of a drip infusion of $10 \mathrm{mg} / \mathrm{m}^{2}$ of cisplatin and $22.5 \mathrm{mg} / \mathrm{m}^{2}$ of irinotecan hydrochloride on days 1-5 and was repeated every 4 weeks (19).

Patients were routinely monitored as follows; 1 through to 6 months, physical examination and serum tumor marker estimation including CA125 every month, CT or MRI images every 3 months; month 7 to year 2, physical examination and serum tumor marker estimation including CA125 every 1-2 months, CT or MRI images every 6 months; years 3 through to 5 , physical examination and serum tumor marker estimation including CA125 every 3-6 months, CT or MRI images annually, years over 6 , physical examination and serum tumor marker estimation including CA125 annually, CT if indicated. Additional clinical assessments were performed as indicated clinically.

The progression of the disease (PD) was defined as the appearance of a new lesion evaluated by a CT of the chest/abdomen or pelvic MR images. The serum levels of tumor markers including CA125 were not used for survival analysis in the present study. The time to relapse was defined as the interval from the date of primary surgery until the date of PD. Survival duration was determined as the time from the date of primary surgery until death or the date of the last follow-up contact.

Statistical methods. The Kaplan-Meier method was used for the calculation of patient survival distribution. The significance of the survival distribution in each group was tested by the log-rank test. The Chi-square test and the Student's t-test for unpaired data were used for statistical analysis. A P-value of $<0.05$ was considered statistically significant. The Stat View software ver.5.0 (SAS Institution Inc., Cary, NC, USA) was used to analyze the data.

\section{Results}

In total, 54 cases with clinical stage I tumors (pT1M0) were enrolled in the present study. The median age was 52 years (range: 36-75) and the median follow-up duration was 48 months (range: 2-166) for relapse-free survival and 50 months (range: 8-166) for overall survival. The median number of the removed lymph nodes in Group A were 35 (range: 19-70) in the pelvic nodes and 20 (range: 12-44) in the para-aortic nodes, respectively.

The characteristics of the patients with ovarian CCC are shown in Table I. Fifteen patients $(28 \%)$ had stage I tumors and 39 patients $(72 \%)$ had stage Ic tumors. In 39 stage Ic tumors, 19 cases (49\%) had malignant ascites or positive peritoneal washing and tumors in 20 cases $(51 \%)$ had ruptured during operation. Clinical characteristics of the two groups were similar, although CAP therapy was more frequently used in Group B ( $\mathrm{p}=0.02)$. In Group A, regimens used were CAP in 10 cases (26\%), paclitaxel and platinum in 5 cases $(13 \%)$ and irinotecan hydrochloride and platinum in 23 cases $(61 \%)$. In Group B, CAP was used in 11 cases $(69 \%)$ and others in 5 cases $(31 \%)$.

Two-year and 5-year relapse-free survival was 84 and $84 \%$ in Group A and 71 and 64\% in Group B. Two-year and 5-year overall survival was 86 and $82 \%$ in Group A and 86 and $72 \%$ in Group B, respectively. Recurrent tumors were detected in 4 cases $(11 \%)$ of Group A; two $(6 \%)$ in the intra-abdominal cavity, one $(3 \%)$ in the pelvic nodes and one $(3 \%)$ in the mediastinal nodes. Four cases $(25 \%)$ from Group B were detected to have recurrent tumors: two (13\%) in the pelvic nodes and two (13\%) in the intra-abdominal cavity. Relapsefree survival according to the pT status is shown in Fig. 1. The pT1a and pT1c tumors in Group B were slightly lower than those tumors in Group B, though the differences were not statistically significant.

A multiple regression analysis was performed in order to detect prognostic factors for relapse-free survival of stage I CCC. Values of age, performance status, stage distribution, ascites or washing status, group distribution and chemotherapy were compared. As a result, group distribution was the only independent prognostic factor for relapse-free survival (Group A vs Group B, hazard ratio, 5.72; p=0.03). Age, performance status, stage distribution and chemotherapy 
Table I. Characteristics of the patients with ovarian clear cell carcinoma confined to the ovary (pT1M0).

\begin{tabular}{|c|c|c|c|}
\hline Stage & Group A $(n=38)$ & Group B $(n=16)$ & P-value \\
\hline Age (years) & & & 0.13 \\
\hline$<54$ & $19(50 \%)$ & $12(75 \%)$ & \\
\hline$>55$ & $19(50 \%)$ & $4(25 \%)$ & \\
\hline Performance status & & & 0.89 \\
\hline 0 & $36(95 \%)$ & $15(94 \%)$ & \\
\hline 1,2 & $2(5 \%)$ & $1(6 \%)$ & \\
\hline Stage & & & 0.30 \\
\hline Stage Ia & $9(24 \%)$ & $6(38 \%)$ & \\
\hline Stage Ic & $29(76 \%)$ & $10(63 \%)$ & \\
\hline Ascites/malignant washing & & & 0.10 \\
\hline Negative & $22(58 \%)$ & $13(81 \%)$ & \\
\hline Positive & $16(42 \%)$ & $3(19 \%)$ & \\
\hline Postoperative chemotherapy & & & 0.02 \\
\hline $\mathrm{CAP}^{\mathrm{a}}$ & $10(26 \%)$ & $11(69 \%)$ & \\
\hline Paclitaxel + platinum & $5(13 \%)$ & $1(6 \%)$ & \\
\hline Irinotecan hydrochloride + platinum & $23(61 \%)$ & $4(25 \%)$ & \\
\hline
\end{tabular}

${ }^{\mathrm{a}} \mathrm{CAP}$, cyclophosphamide + doxorubicin + cisplatin.

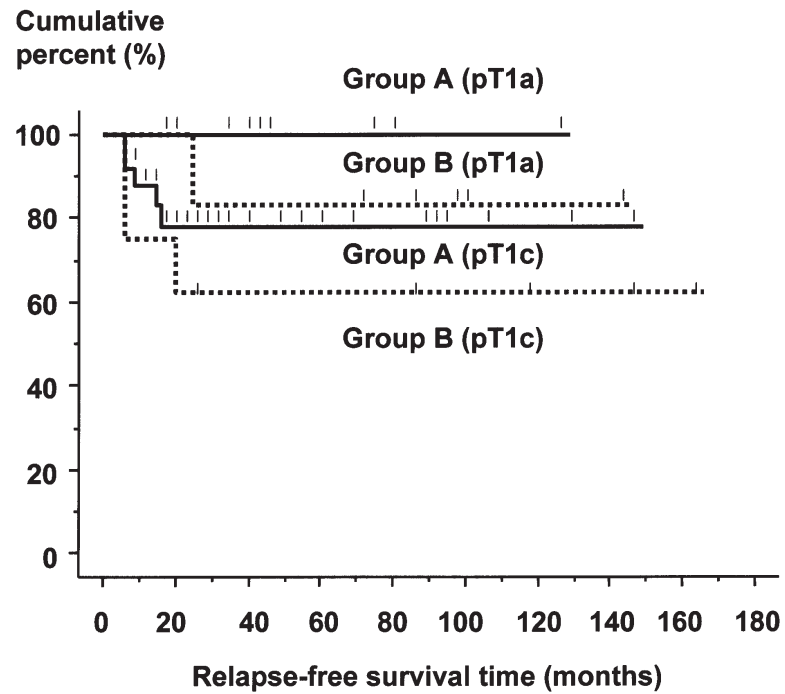

Figure 1. A Kaplan-Meier curve comparing the relapse-free survival of Group A $(n=38)$ and Group B $(n=16)$ according to the pT status. Group A included 9 cases of pT1a and 29 cases of pT1c tumors and Group B contained 6 cases of pT1a and 10 cases of pT1c tumors. Recurrent tumors were detected in 4 cases $(11 \%)$ of Group A and four cases (25\%) of Group B.

were not significant prognostic factors (Table II). A multiple regression analysis was performed for detecting the prognostic factors for overall survival of stage I CCC using the same values as described in Table II, though there were no significant prognostic factors (data not shown).

\section{Discussion}

The number of removed nodes determines the radicality of lymphadenectomy. One report suggested that $\sim 81$ lymph nodes (range, 49-128) are located between the pelvis and the aortic area; 50 at the pelvis and 31 at the aorta (23). Pereira et al reported that $\sim 25$ pelvic lymph nodes and 13 aortic lymph nodes are adequate for the detection of nodal involvement in epithelial ovarian cancer (24). According to these criteria, insufficient lymphadenectomy was documented in 4 cases $(11 \%)$ in the pelvis and 2 cases $(5 \%)$ in the para-aortic nodes, suggesting that lymphadenectomy in our series of CCC could be adequate for further evaluation.

The incidence of positive retroperitoneal lymph nodes in each subtype of stage I (pT1) ovarian cancer was relatively high, ranging up to $20 \%$ (25-27). A report (28) demonstrated that serous tumors had a higher incidence of lymph node metastasis than non-serous tumors and another report (20) demonstrated that lymph node involvement of the CCC disease was observed in $9.1 \%$ in pT1a and $7.1 \%$ in pT1c tumors. It is suggested that the CCC tumors have a lower incidence of lymphatic involvement compared with other histological subtypes.

In the early stages of ovarian cancer, the significance of retroperitoneal lymph node status upon survival was not determined. While certain reports showed a positive relationship with node status and survival $(27,29,30)$, others showed survival similarity between node-positive and negative tumors $(31,32)$. A large study with completely staged CCC disease revealed that the positive lymph node was significantly correlated with worse prognosis in pT1 tumors (20). However, another large study concluded that lymphadenectomy significantly improved 5-year survival of non-clear cell type tumors and that the survival of CCC cases were not improved by lymphadenectomy (33). This discrepancy might be explained by the difference of sensitivity to postoperative chemotherapy or by an unbalanced distribution of the subtypes of stage I tumors, because positive 
Table II. Multiple regression survival analysis for the patients with ovarian clear cell carcinoma confined to the ovary (pT1M0).

\begin{tabular}{|c|c|c|c|}
\hline Variables & Hazard ratio & 95\% Confidence interval & P-value \\
\hline Age (years) & & & 0.49 \\
\hline$<54$ & 1 & & \\
\hline$>55$ & 0.62 & $0.16 ; 2.44$ & \\
\hline Performance status & & & 0.42 \\
\hline 0 & 1 & & \\
\hline 1,2 & 2.38 & $0.25 ; 22.73$ & \\
\hline Stage & & & 0.96 \\
\hline Stage Ia & 1 & & \\
\hline Stage Ic & 1.05 & $0.14 ; 7.88$ & \\
\hline Ascites/malignant washing & & & 0.14 \\
\hline Negative & 1 & & \\
\hline Positive & 3.35 & $0.68 ; 16.54$ & \\
\hline Group & & & 0.03 \\
\hline Group A & 1 & & \\
\hline Group B & 5.72 & $1.21 ; 27.03$ & \\
\hline Postoperative chemotherapy & & & 0.43 \\
\hline $\mathrm{CAP}^{\mathrm{a}}$ & 1 & & \\
\hline Paclitaxel + platinum & 3.50 & $0.23 ; 17.77$ & \\
\hline Irinotecan hydrochloride + platinum & 2.34 & $0.61 ; 19.96$ & \\
\hline
\end{tabular}

${ }^{\mathrm{a} C A P}$, cyclophosphamide + doxorubicin + cisplatin.

peritoneal cytology was correlated with a worse prognostic in FIGO stage I tumors (20).

The tumor relapse in the pelvic or para-aortic nodes were possibly less observed in Group A (3\%) than in Group B $(13 \%, \mathrm{p}=0.14)$. Although the difference was not significant, relapse at the lymph nodes might have been reduced by comprehensive lymphadenectomy. Recurrence of intraabdominal space occurred in $8 \%$ in Group $\mathrm{A}$ and $13 \%$ in Group B, suggesting the similarity of the abdominal recurrence rates of the two groups.

The study, called Adjuvant ChemoTherapy in Ovarian Neolasm (ACTION), documented that the benefits of adjuvant chemotherapy was limited in non-optimally staged early-stage ovarian cancer (34). This study included only $14 \%$ of CCC, and the distribution of the histological subtypes might have confused the results due to chemosensitivity difference. In the present study, complete surgical staging was the only significant factor for relapse-free survival of stage I CCC tumors. This might support the therapeutic effects of lymphadenectomy of ovarian neoplasms, especially CCC whose tumors show a relative resistance to anti-cancer drugs. Several explanations are possible for the improvement of survival: comprehensive lymphadenectomy might remove the micrometastasis disease which could not be detected by conventional histopathological methods $(35,36)$ and the significance would be greater if the lesion included chemoresistant clones. Otherwise, the significance was obvious simply because Group B contained some cases of true stage IIIc (pT1N1) disease. Based on a previous study, there is the possibility of contamination of up to $10 \%$ of stage I CCC cases whose lymph nodes have metastasis, thus the cases would worsen the prognosis of non-surgically staged disease. The results suggest that comprehensive lymphadenectomy for clinical stage I CCC cases is associated not only with diagnostic significance but also with therapeutic effects. Thus, we could not easily omit lymphadenenctomy even for the fertility-sparing operation if the tumor of the patient was diagnosed as CCC.

Complications with lymphadnectomy are to some extent unavoidable. Actually, median operation time was longer and more cases required a blood transfusion (37). Nevertheless, the need of maximal optimal surgery including lymphadenectomy is emphasized by the evidence that the extent of lymphadenectomy increased the survival rates of stage I ovarian cancer patients (33).

As every case received chemotherapy, we could not compare the presence or absence of the therapy. In our retrospective study, however, there was no significant difference in regimens of postoperative chemotherapy for relapse-free and overall survival. We have to wait for the results of a large international study which has started to compare irinotecan hydrochloride plus cisplatin with paclitaxel plus carboplatin for postoperative chemotherapy for CCC (GCIG/JGOG 3017).

In the aspect of molecular characteristics as well as clinical behavior, it is hypothesized that CCC belongs to a different entity from other histological subtypes of ovarian carcinoma. There are many publications supporting this hypothesis and molecular markers such as HNF-1ß $(38,39)$, PPM1D (40), APPBP2 (40), WT1(41), WT1-AS(41) and ABCF2 (42) might be used for targets of CCC in the near future. 
The present study implied there are diagnostic and prognostic effects in complete surgical staging for the treatment of CCC confined to the ovary. However, this was a limited retrospective study and could not suggest the significant therapeutic impact of comprehensive lymphadenectomy plus chemotherapy upon survival. We need to further investigate the therapeutic effects of comprehensive lymphadenectomy in a large prospective study using single regimen, which would be selected by a large study, such as GCIG/JGO3017.

\section{References}

1. Bray F, Loos AH, Tognazzo S and La Vecchia C: Ovarian cancer in Europe: Cross-sectional trends in incidence and mortality in 28 countries, 1953-2000. Int J Cancer 113: 977-990, 2005.

2. Edwards BK, Brown ML, Wingo PA, Howe HL, Ward E, Ries LA, Schrag D, Jamison PM, Jemal A, Wu XC, Friedman C, Harlan L, Warren J, Anderson RN and Pickle LW: Annual report to the nation on the status of cancer, 1975-2002, featuring population-based trends in cancer treatment. J Natl Cancer Inst 97: 1407-1427, 2005

3. McGuire WP, Hoskins WJ, Brady MF, Kucera PR, Partridge EE, Look KY, Clarke-Pearson DL and Davidson M: Cyclophosphamide and cisplatin compared with paclitaxel and cisplatin in patients with stage III and IV ovarian cancer. N Engl J Med 334: 1-6, 1996.

4. Rose PG, Fusco N, Fluellen L and Rodriguez M: Second-line therapy with paclitaxel and carboplatin for recurrent disease following first-line therapy with paclitaxel and platinum in ovarian and peritoneal carcinoma. J Clin Oncol 16: 1494-1497, 1998.

5. Dizon DS, Hensley ML, Poynor EA, Sabbatini P, Aghajanian C, Hummer A, Venkatraman E and Spriggs DR: Retrospective analysis of carboplatin and paclitaxel as initial second-line therapy for recurrent epithelial ovarian carcinoma: application toward a dynamic disease state model of ovarian cancer. J Clin Oncol 20: 1238-1247, 2002.

6. Parmar MK, Ledermann JA, Colombo N, du Bois A, Delaloye JF, Kristensen GB, Wheeler S, Swart AM, Qian W, Torri V, Floriani I, Jayson G, Lamont A and Trope C: ICON and AGO Collaborators: Paclitaxel plus platinum-based chemotherapy versus conventional platinum-based chemotherapy in woman with relapsed ovarian cancer: the ICON4/AGO-OVAR-2.2 trial. Lancet 361: 2099-2106, 2003

7. Schiller W: Mesonephroma ovarii. Am J Cancer 35: 1-21, 1939.

8. Serov SF, Scully RE and Sobin LH: International histologic classification of tumors. Histologic typing of ovarian tumors. WHO, Geneva, No.9. 1978.

9. Goff BA, Sainz de la Cuesta R, Muntz HG, Fleischhacker D, Ek M, Rice LW, Nikrui N, Tamimi HK, Cain JM, Greer BE and Fuller AF Jr: Clear cell carcinoma of the ovary: a distinct histologic type with poor prognosis and resistance to platinumbased chemotherapy in stage III disease. Gynecol Oncol 60: 412-417, 1996.

10. Recio FO, Piver MS, Hempling RE and Driscoll DL: Lack of improved survival plus increase in thromboembolic complications in patients with clear cell carcinoma of the ovary treated with platinum versus nonplatinum-based chemotherapy. Cancer 78 : 2157-2163, 1996.

11. Sugiyama T, Kamura T, Kigawa J, Terakawa N, Kikuchi Y, Kita T, Suzuki M, Sato I and Taguchi K: Clinical characteristics of clear cell carcinoma of the ovary. Cancer 88: 2584-2589, 2000.

12. Pectasides D, Fountzilas G, Aravantinos G, Kalofonos C, Efstathiou H, Farmakis D, Skarlos D, Pavlidis N, Economopoulos T and Dimopoulos MA: Advanced stage clearcell epithelial ovarian cancer: The Hellenic cooperative oncology group experience. Gynecol Oncol 102: 285-291, 2006.

13. Enomoto T, Kuragaki C, Yamasaki M, Sugita N, Otsuki Y, Ikegami H, Matsuzaki N, Yamada T, Wakimoto A and Murata Y, for the Gynecologic Oncology Group of Osaka: Is clear cell carcinoma and mucinous carcinoma of the ovary sensitive to combination chemotherapy with paclitaxel and carboplatin? Proc Am Soc Clin Oncol 22: 447 (abstr 1797), 2003.
14. Ho CM, Huang YJ, Chen TC, Huang SH, Liu FS, Chang Chien CC, Yu MH, Mao TL, Wang TY and Hsieh CY: Pure-type clear cell carcinoma of the ovary as a distinct histological type and improved survival in patients treated with paclitaxel-platinumbased chemotherapy in pure-type advanced disease. Gynecol Oncol 94: 197-203, 2004.

15. Utsunomiya H, Akahira J, Tanno S, Moriya T, Toyoshima M, Niikura H, Ito K, Morimura Y, Watanabe $\mathrm{Y}$ and Yaegashi N: Paclitaxel-platinum combination chemotherapy for advanced or recurrent ovarian clear cell adenocarcinoma: a multicenter trial. Int J Gynecol Cancer 16: 52-56, 2006.

16. Ho CM, Chien TY, Shih BY and Huang SH: Evaluation of complete surgical staging with pelvic and para-aortic lymphadenectomy and paclitaxel plus carboplatin chemotherapy for improvement of survival in stage I ovarian clear cell carcinoma. Gynecol Oncol 88: 394-399, 2003.

17. Takano M, Kikuchi Y, Yaegashi N, Kuzuya K, Ueki M, Tsuda H, Suzuki M, Kigawa J, Takeuchi S, Tsuda H, Moriya T and Sugiyama T: Clear cell carcinoma of the ovary: a retrospective multicentre experience of 254 patients with complete surgical staging. Br J Cancer 94: 1369-1374, 2006.

18. Adachi S, Ogasawara T, Yamasaki N, Shibahara H, Kanazawa R, Tsuji Y, Takemura T and Koyama K: A pilot study of CPT-11 and cisplatin for ovarian clear cell adenocarcinoma. Jpn J Clin Oncol 29: 434-437, 1999.

19. Kita T, Kikuchi Y, Kudoh K, Takano M, Goto T, Hirata J, Tode $\mathrm{T}$ and Nagata I: Exploratory study of effective chemotherapy to clear cell carcinoma of the ovary. Oncol Rep 7: 327-331, 2000.

20. Takano M, Kikuchi Y, Yaegashi N, Suzuki M, Tsuda H, Sagae S, Udagawa Y, Kuzuya K, Kigawa J, Takeuchi S, Tsuda H, Moriya $\mathrm{T}$ and Sugiyama T: Adjuvant chemotherapy with irinotecan hydrochloride and cisplatin for clear cell carcinoma of the ovary. Oncol Rep 16: 1301-1306, 2006.

21. Russell P: Surface epithelial-stromal tumors of the ovary. In: Blaustein's Pathology of the Female Genital Tract. Kurman RJ (ed). 4th edition, Springer, New York, pp752-762, 1995.

22. F.I.G.O. Cancer Committee: Staging announcement. Gynecol Oncol 25: 383, 1986.

23. Panici PB, Scambia G, Baiocchi G, Matonti G, Capelli A and Mancuso S: Anatomical study of para-aortic and pelvic lymph nodes in gynecologic malignancies. Obstet Gynecol 79: 498-502, 1992.

24. Pereira A, Magrina JF, Rey V, Cortes M and Magtibay PM: Pelvic and aortic lymph node metastasis in epithelial ovarian cancer. Gynecol Oncol 105: 604-608, 2007.

25. Cass I, Li AJ, Runowicz CD, Fields AL, Goldberg GL, Leuchter RS, Lagasse LD and Karlan BY: Pattern of lymph node metastases in clinically unilateral stage I invasive epithelial ovarian carcinomas. Gynecol Oncol 80: 56-61, 2001.

26. Morice P, Joulie F, Camatte S, Atallah D, Rouzier R, Pautier P, Pomel C, Lhomme C, Duvillard P and Castaigne D: Lymph node involvement in epithelial ovarian cancer: analysis of 276 pelvic and paraaortic lymphadenectomies and surgical implications. J Am Coll Surg 197: 198-205, 2003.

27. Negishi H, Takeda M, Fujimoto T, Todo Y, Ebina Y, Watari H, Yamamoto R, Minakami H and Sakuragi N: Lymphatic mapping and sentinel node identification as related to the primary sites of lymph node metastasis in early stage ovarian cancer. Gynecol Oncol 94: 161-166, 2004.

28. Takeshima N, Hirai Y, Umayahara K, Fujiwara K, Takizawa K, and Hasumi K: Lymph node metastasis in ovarian cancer: Difference between serous and non-serous primary tumors. Gynecol Oncol 99: 427-431, 2005.

29. Kanazawa K, Suzuki T and Tokashiki M: The validity and significance of substage IIIC by node involvement in epithelial ovarian cancer: impact of nodal metastasis on patient survival. Gynecol Oncol 73: 237-241, 1999.

30. Sakuragi N, Yamada H, Oikawa M, Okuyama K, Fujino T, Sagawa T and Fujimoto S: Prognostic significance of lymph node metastasis and clear cell histology in ovarian carcinoma limited to the pelvis (pT1M0 and pT2M0). Gynecol Oncol 79: 251-255, 2000.

31. Onda T, Yoshikawa H, Yasugi T, Mishima M, Nakagawa S, Yamada M, Matsumoto K and Taketani Y: Patients with ovarian carcinoma upstaged to stage III after systematic lymphadenctomy have similar survival to Stage I/II patients and superior survival to other Stage III patients. Cancer 83: 1555-1560, 1998.

32. Cliby WA, Aletti GD, Wilson TO and Podratz KC: Is it justified to classify patients to stage IIIc epithelial ovarian cancer based on nodal involvement only? Gynecol Oncol 103: 797-801, 2006 . 
33. Chan JK, Munro EG, Cheung MK, Husain A, Teng NN, Berek JS and Osann K: Association of lymphadenectomy and survival in stage I ovarian cancer. Obstet Gynecol 109: 12-19, 2007.

34. Trimbos JB, Vergote I, Bolis G, Vermorken JB, Mangioni C, Madronal C, Franchi M, Tateo S, Zanetta G, Scarfone G, Giurgea L, Timmers P, Coens C and Pecorelli S: EORTCACTION collaborators: European Organisation for Research and Treatment of Cancer-Adjuvant ChemoTherapy in Ovarian Neoplasm: Impact of adjuvant chemotherapy and surgical staging in early-stage ovarian carcinoma: European Organisation for Research and Treatment of Cancer-Adjuvant ChemoTherapy in Ovarian Neoplasm trial. J Natl Cancer Inst 95: 113-125, 2003.

35. Suzuki M, Ohwada M, Saga Y, Kohno T, Takei Y and Sato I: Micrometastic p53-positive cells in the lymph nodes of early stage ovarian cancer: prognostic significance. Oncology 60 : 170-175, 2001.

36. Yabushita H, Shimazu M, Yamada H, Sawaguchi K, Noguchi M, Nakanishi M and Kawai M: Occult lymph node metastasis detected by cytoleratin immunohistochemistry predict recurrence in node-negative endometrial cancer. Gynecol Oncol 80: 139-144, 2001.

37. Maggioni A, Benedetti Panici P, Dell'Anna T, Landoni F, Lissoni A, Pellegrino A, Rossi RS, Chiari S, Campagnutta E, Greggi S, Angioli R, Manci N, Calcagno M, Scambia G, Fossati R, Floriani I, Torri V, Grassi R and Mangioni C: Randomised study of systemic lymphadenectomy in patients with epithelial ovarian cancer macroscopically confined to the pelvis. Br J Cancer 95: 699-704, 2006.
38. Tsuchiya A, Sakamoto M, Yasuda J, Chuma M, Ohta T, Ohki M, Yasugi T, Taketani Y and Hirohashi S: Expression profiling in ovarian clear cell carcinoma: identification of hepatocyte nuclear factor-1 beta as a molecular marker and a possible molecular target for therapy of ovarian clear cell carcinoma. Am J Pathol 163: 2503-2512, 2003.

39. Kato N, Sasou S and Motoyama T: Expression of hepatocyte nuclear factor-1beta (HNF-1beta) in clear cell tumors and endometriosis of the ovary. Mod Pathol 19: 83-89, 2006.

40. Hirasawa A, Saito-Ohara F, Inoue J, Aoki D, Susumu N, Yokoyama T, Nozawa S, Inazawa J and Imoto I: Association of 17q21-q24 gain in ovarian clear cell adenocarcinomas with poor prognosis and identification of PPMD1 and APPBP2 as likely amplification targets. Clin Cancer Res 9: 1995-2004, 2003.

41. Kaneuchi M, Sasaki M, Tanaka Y, Shiina H, Yamada H, Yamamoto R, Sakuragi N, Enokida H, Verma M and Dahiya R: WT1 and WT1-AS genes are inactivated by promoter methylation in ovarian clear cell adenocarcinoma. Cancer 104: 1924-1930, 2005.

42. Tsuda H, Ito YM, Ohashi Y, Wong KK, Hashiguchi Y, Welch WR, Berkowitz RS, Birrer MJ and Mok SC: Identification of overexpression and amplification of ABCF2 in clear cell ovarian adenocarcinoma by cDNA microarray analysis. Clin Cancer Res 11: 6880-6888, 2005. 